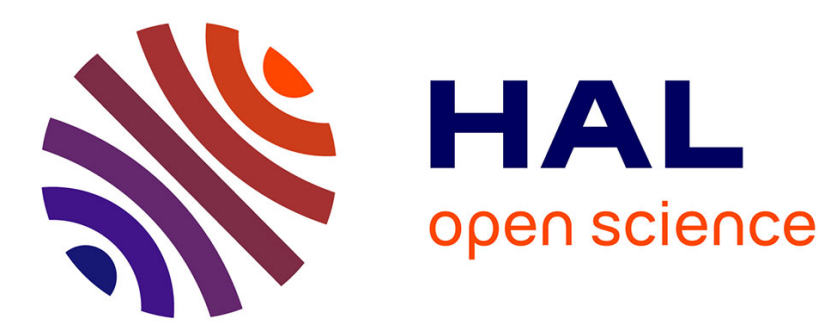

\title{
Drug therapy of cancer
}

Curt Peterson

\section{To cite this version:}

Curt Peterson. Drug therapy of cancer. European Journal of Clinical Pharmacology, 2011, 67 (5), pp.437-447. 10.1007/s00228-011-1011-x . hal-00671936

\section{HAL Id: hal-00671936 https://hal.science/hal-00671936}

Submitted on 20 Feb 2012

HAL is a multi-disciplinary open access archive for the deposit and dissemination of scientific research documents, whether they are published or not. The documents may come from teaching and research institutions in France or abroad, or from public or private research centers.
L'archive ouverte pluridisciplinaire HAL, est destinée au dépôt et à la diffusion de documents scientifiques de niveau recherche, publiés ou non, émanant des établissements d'enseignement et de recherche français ou étrangers, des laboratoires publics ou privés. 
110130

\title{
Drug therapy of cancer
}

\author{
Curt Peterson \\ Professor, MD, PhD \\ Departments of Clinical Pharmacology and Oncology \\ University hospital \\ SE-581 85 Linköping \\ Sweden
}

curt.peterson@liu.se, tel: +46101031090, fax: +4613104195 


\begin{abstract}
Cancer chemotherapy was introduced at the same time as antibacterial chemotherapy but has not at all been such a success. However, there is a growing optimism in oncology today due to the introduction of several more or less target specific drugs as complement to the conventional cytotoxic drugs introduced half a century ago. The success in the treatment of chronic myelogenous leukemia by imatinib, inhibiting the bcr-abl activated tyrosine kinase thereby interrupting the signal transduction pathways that lead to leukemic transformation. with impressive survival benefit has paved the way for this new optimism. Another success story is the introduction of trastuzumab in breast cancers overexpressing the HER-2 receptor. In contrast, there has been little progress in other malignancies like metastatic malignant melanoma although very recently, clinical trials with new targeted drugs have shown increased survival. All major pharmaceutical companies now have ambitious development programs in the cancer area. However, the high costs of the novel drugs cause economic distress in the health care system in many countries leading to an intense debate on the costeffectiveness of these drugs in relation to other health care activities.
\end{abstract}

\title{
Introduction
}

Cancer is a major challenge for the health care in the Western world with an aging population. About 2.4 millions new cases were diagnosed within a population of about 470 millions in the European Union in 2006 and about 1.2 million cancer deaths occurred (1). In men, prostate cancer was the most common with 301,500 new cases followed by lung cancer 194,400, and colorectal cancer 163,100 cases. In women, breast cancer was by far the most common with 319,900 new cases followed by colorectal cancer 134,100 cases. The overall cancer survival in the Western world has slowly increased over the last decades. For patients diagnosed 1995 - 1999 in 23 European countries, the 5-years-survival was $44.8 \%$ for men and $54.6 \%$ for women with large variations between diagnoses and countries (2). The improved survival is not only due to improved treatment but also to the introduction of screening programs for early detection like cervical smear and mammography in women and also by intensified cancer prevention e.g. anti-smoking programs.

\section{Cancer drug discovery and development}

Enormous research efforts have been spent during the last 50 years on the development of new cancer drugs by the pharmaceutical industry, academic institutions and governmental organisations like The National Cancer Institute (NCI) in the US. Despite this, the progress in 
the treatment of the most common diseases has been slow. Why hasn't it been faster? In the retrospect, some crucial factors can be identified. There are more pronounced differences in the biochemical machinery between bacteria and human cells than between cancer cells and normal cells making it difficult to kill cancer cells selectively. Cancer drug discovery was for a long time based on testing of more or less randomly selected compounds for activity against rapidly proliferating murine leukemic cells. In an attempt to improve the screening, the NCI launched the "In Vitro Cell Line Screening Project" in 1990 (3). It utilizes 60 wellcharacterized human tumor cell lines representing leukemia, melanoma, and cancers of the lung, colon, brain, ovary, breast, prostate and kidney. The aim was to prioritize for further evaluation compounds with selective growth inhibition or cell killing of particular tumor cell lines.. Certain drugs with unique mechanisms of actions like the proteasome inhibitor bortezomib (Velcade ${ }^{\circledR}$ ), used in multiple myeloma (3), have been successfully developed by this strategy but overall the improvement compared to previous screening models is not obvious.

One cruzial factor is that the experimental models with rapidly growing cell lines and transplantable murine leukemia do not reflect the heterogeneity of human tumors. In human cancer with an unstable genome, the heterogeneity progresses during many cell generations before the disease can be diagnosed and treatment initiated. As a result, the tumor already at diagnosis may contain subclones responding differently to treatment, the consequences of which have been underestimated. This is obvious in the research on drug resistance, which is the major obstacle for successful chemotherapy (4). Resistance can easily be induced in cell lines by exposing the cells to successively increasing drug concentrations during several cell generations. By comparison with the parental cell line, many resistance mechanisms have been identified e g overexpression of efflux pumps for drugs of natural origin, increased DNA repair capacity, and increased glutathione transferase activity. Some well-known mechanisms like overexpression of the membrane efflux protein, p-glycoprotein, can be successfully reversed in resistant cell lines by simultaneous exposure to non-toxic substances like nonimmunosuppressive cyclosporine analogues competing with the pump mechanism. However, attempts to transfer these experimental results to the clinic by predictive sensitivity testing of tumor cells in vitro and resistance reversal by simultaneous administration of reversing agents have failed due to the heterogeneity of the tumor cell population in patients making clinical resistance a multi-factorial problem (5). 


\section{Conventional cytotoxic drugs}

From the introduction of nitrogen mustard during World War II evolving from research in military laboratories on war gases, about 60 cytotoxic drugs have been approved for clinical use. Most of them are now off-patent and the interest has shifted dramatically to more target specific drugs, especially monoclonal antibodies and orally delivered small molecule tyrosine kinase inhibitors. Many of the old cytotoxic drugs are the result of serendipitous discoveries. As an example, Barnett Rosenberg at Michigan State University, in the 1960ies, explored the effects of an electrical field on bacterial growth and found that the bacteria ceased to divide (6). However, it turned out that the effect was not due to the electrical field as such but to an electrolysis product of the platinum electrode. This discovery soon initiated a series of investigations on the effects of platinum compounds on cell division, culminating in the synthesis of cisplatin, which was approved by the Food and Drug Administration (FDA) in 1978. More than 3000 platinum compounds have been synthesized and tested in screening systems (7). Only 30 of these have entered clinical trials and so far only four have reached the market: cisplatin, carboplatin, oxaliplatin and nedaplatin (only in Japan).

Anthracyclines are a class of drugs derived from a Streptomyces variant originally found in soil from the shore of the Adriatic Sea. The anthracyclines, being natural products, are effective against more cancer types than any other class of chemotherapy agents (8). Daunorubicin, produced naturally by Streptomyces peucetius was the first anthracycline in clinical use and is still after 40 years widely used in the treatment of acute myelogenous leukemia. Doxorubicin, with a broader antitumoral spectrum, was then developed from a mutated strain of Steptomyces peucetius. The reason for the difference in therapeutic spectrum between daunorubicin and doxorubicin is not clear. Anthracyclines exert several cellular effects. Most important for the therapeutic effect is the interaction with the topoisomerase II enzyme preventing religation of double stranded DNA breaks and thereby blocking DNA transcription and replication. One important adverse effect is the cumulative cardiotoxicity limiting their usefulness. In order to improve the therapeutic index, a vast number of semisynthetic analogues of daunorubicin and doxorubicin have been developed and tested. Epirubicin, only differing from doxorubicin by the spatial orientation of one hydroxyl group, was introduced shortly before doxorubicin patent expiration and is now the most used anthracycline in Europe because of less cardiotoxicity but probably also less effective so the advantage is controversial and it was approved much later in the US. 
Nucleoside analogs are a major class of chemotherapeutic agents for the treatment of cancer and viral diseases. The effectiveness of these agents as antitumor drugs was established already in the 1960s with the pyrimidine analogue 5-fluorouracil (9) and the thiopurines, 6mercaptopurine and 6-thioguanine (10). Subsequently, nucleosides, altered in the carbohydrate moiety, became the focus for the development of nucleic acid precursor analogs. The recognition that the pyrimidine nucleoside analog cytarabine, had activity in acute myelogenous leukemia generated enthusiasm for the investigation of congeners that might have a broader spectrum of activity (11). This was achieved with the development of gemcitabine, another carbohydrate-modified analog of deoxycytidine, which is effective against a variety of solid tumors (12). In parallel with the emergence of gemcitabine came the investigations that established that the family of purine nucleoside analogs, fludarabine, cladribine, clofarabine and nelarabine, have major activity in indolent B-cell malignancies. One of the remarkable features that remain unexplained about nucleoside analogs is how drugs with such similar structures, sharing metabolic pathways and elements of their mechanisms of action, show such diversity in their clinical activities.Inhibition of the production of tetrahydrofolic acid, important for the synthesis of purines and pyrimidines, was identified as a target for anticancer chemotherapy long ago. Methotrexate is still a cornerstone in the treatemnt of childhood leukemia both as high-dose therapy $(5-8 \mathrm{~g} / \mathrm{m} 2)$ followed by leucovorin rescue and as low dose oral maintenace treatment $(20 \mathrm{mg} / \mathrm{m} 2)$ once a week. Recently an interestingantifolate, pemetrexed (Alimta®) was introduced(13). Pemetrexed was first approved in the treatment of mesothelioma based on a study comparing pemetrexed and cisplatin versus cisplatin alone showing an increase in median overall survivial from 9.3 to 12.1 months in the combination arm (14). It has also shown effect in non-small cell lung cancer at moderate toxicity (15).

Drugs that target microtubules are among the most commonly prescribed anticancer therapies. Although the mechanisms by which perturbation of microtubule function leads to selective death of cancer cells remain unclear, several new microtubule-targeting compounds are undergoing clinical testing. Much effort has been focused on overcoming some of the problems associated with taxane-based therapies, including formulation and administration difficulties and susceptibility to resistance conferred by P-glycoprotein. The well-known taxanes, paclitaxel and docetaxel are poorly water-soluble requiring the use of solvents in the formulations and pre-treatment of patients with steroids and antihistamines to avoid hypersensitivity reactions to the solvents. To avoid this, nanoparticle formulations are being 
developed and an albumin-linked formulation of paclitaxel (Abraxane®) has been approved based on a study in metastatic breast cancer (16). It can be rapidly infused without any pretreatment. Currently another nanoparticular formulation of paclitaxel, Paclical ${ }^{\circledR}$, is in phase 3 trial in recurrent ovarian cancer in Europe comparing Paclical ${ }^{\circledR}(250 \mathrm{mg} / \mathrm{m} 2$ paclitaxel) without pretreatment with conventional paclitaxel (Taxol $175 \mathrm{mg} / \mathrm{m} 2$ ) in both cases combined with carboplatin every third week. Recently cabazitaxel (Jevtana®) was approved by the FDA for second-line treatment of metastatic hormone refractory prostate cancer based on a study in patients previously treated with docetaxel. The median overall survival with cabazitaxel was 15.1 months compared to 12.7 months in the mitoxantrone arm, both drugs combined with prednisolone (17). The main rational for the development of cabazitaxel was that it is not a substrate for the p-glycoprotein efflux pump but pretreatment of patients is required due to the risk of hypersensitivity reactions.

Errors in the mitosis process can provide a source of genomic instability that is typically associated with tumorigenesis. Many mitotic regulators are aberrantly expressed in tumour cells. These proteins could therefore make useful therapeutic targets. The kinases aurora-A, $\mathrm{B}$ and $-\mathrm{C}$ represent a family of such targets. In recent years, several small-molecule aurora kinase inhibitors have been developed that exhibit preclinical activity against a wide range of solid tumors. Preliminary clinical data from phase I trials have largely been consistent with cytostatic effects, with disease stabilization as the best response achieved in solid tumors. Objective responses have been noted in leukemia patients (18).

\section{First breakthrough - intermittent combination chemotherapy}

The principal obstacles to successful chemotherapy are toxicity to normal dividing cells eg in the bone marrow and the development of drug resistance. Pioneering experimental work in the 1950ies by Howard Skipper and Frank Schabel at the Southern Research Institute, Birmingham, Alabama demonstrated that intermittent combination chemotherapy gave improved results as compared to single agent continuous treatment (19). The first clinical break-through was the MOPP regimen in Hodgkin's lymphoma introduced by deVita and collaborators in the mid 1960ies. By combining mustin (an alkylating agent), vincristine (a mitotic inhibitor, trade name Oncovine ${ }^{\circledR}$ ) with procarbazine (mechanism of action poorly understood) and prednisone, a high cure rate could be obtained (20). Another success story is the treatment of disseminated testicular cancer by the combination of 
cisplatin + vinblastine + bleomycin introduced by Larry Einhorn in the 1980ies, changing the cure rate from 5 to $60 \%$ (21). Vinblastine was later replaced by etoposide reducing side effects and further improving the cure rate.

The intermittent administration of cancer chemotherapy eg every third week means that steady-state drug concentrations are not reached and that plasma concentration monitoring has not proved to be of value to individualize the treatment like in some other therapeutic areas like epilepsy and depression. However, in high dose methotrexate treatment, plasma concentrations are routinely monitored for the dosing of the antidote leukovorin.

\section{Adjuvant chemotherapy}

As predicted by studies in animal models, cytotoxic drugs are most effective when used in patients with small tumors. Thus early detection is important for sucessfull treatment. Another strategy developed from this knowledge is the concept of adjuvant chemotherapy after initial surgery eliminating all detectable tumors. In 1976, Bonadonna and coworkers at the National Cancer Institute in Milan presented the first report on the efficacy of adjuvant treatment for lymph node-positive breast cancer by CMF (cyclophosphamide, methotrexate and fluorouracil) (22). Results of 30 years follow-up are now available confirming the long lasting effect (23). Thereafter a long series of studies have been performed to define the best drug combination and schedule. Currently, 3 - 4 cycles of an anthracycline + cyclophosphamide followed by 3 - 4 cycles of a taxane is a common regimen. The problem with adjuvant chemotherapy is that many patients, cured by surgery and local radiotherapy, are treated and receiving side effects but so far it is not possible to identify only those patients in need of adjuvant chemotherapy. The concept of adjuvant therapy has now been adopted also in other tumor types like colorectal cancer and lung cancer.

\section{Novel targeted drugs and signal transduction inhibitors}

Recent advances in cell biology have contributed significantly to our understanding of cancer genetics and tumor formation. Current knowledge suggests that a series of mutations in the normal genome precede the transformation of a normal cell into a cancerous cell. These mutations can activate growth-stimulating or cell death blocking proteins or inactivate growth inhibiting or cell death stimulating proteins. Molecular biology approaches to study cell biology have uncovered signalling networks that regulate proliferation and survival. Many of these networks are altered in cancer cells, and these alterations have a genetic basis caused by 
somatic mutations in genes involved in the control of cell growth and cell death. The result will be malignant cells devoid of normal growth control and with invasive properties. The best characterized growth factors are EGF (epidermal growth factor), PDGF (platelet-derived growth factor) and VEGF (vascular endothelium growth factor). These are produced by cells in the surrounding and act on cell surface receptors with a common structure: an extracellular ligand-binding part, a transmembrane part and an intracellular part with tyrosine kinase activity. Activation of these tyrosine kinases causes a cascade reaction ultimately leading to DNA synthesis and cell division. Two different strategies have been adopted to develop drugs blocking growth factors and their receptors. One strategy has been to produce antibodies which block the growth factor or its receptor. The alternative strategy has been to develop small molecules acting intracellular by blocking the enzymatic function of the tyrosine kinases thereby inhibiting the signalling cascade.

\section{Tyrosine kinase inhibitors}

The classic example of targeted development is imatinib (Glivec $®$ ), a small molecule which inhibits a signaling kinase. The genetic abnormality causing chronic myelogenous leukemia (CML) has been known for a long time to be a chromosomal translocation (9:22, the Philadelphia chromosome) creating an abnormal fusion protein, bcr-abl, which signals aberrantly, leading to uncontrolled proliferation of the leukemia cells. Imatinib inhibits this kinase. Unlike so many other anti-cancer agents, imatinib was the result of rational work. Brian Druker, working at Oregon Health Science University, had extensively studied the abnormal enzyme kinase in CML (24). He reasoned that inhibiting this kinase with a drug would control the disease and have little effect on normal cells. Druker collaborated with chemists at Novartis, who developed several candidate inhibitors. From these, imatinib was found to have the most promise in laboratory experiments. When this small molecule given daily orally is used to treat patients with chronic-phase CML, $90 \%$ achieve complete haematological remission. Excellent 5-year survival data have recently been published (25). Imatinib also inhibits the KIT receptor on gastrointestinal stroma cell tumors and is the drug of choice in non-operable patients. New analogs, nilotinib (Tasigna ${ }^{\circledR}$ ) and dasatinib (Sprycel@) have been developed and first approved for the treatment of imatinib resistant CML patients and recently also for first line therapy.

Erlotinib (Tarceva®) specifically targets the EGFR tyrosine kinase, which is highly expressed and occasionally mutated in various forms of cancer. It binds in a reversible fashion to the 
ATP binding site of the receptor (26). For the signal to be transmitted, two members of the EGFR family need to come together to form a homodimer. Phosphorylation then causes a conformational change in the intracellular structure, exposing a further binding site for binding proteins that cause a signal cascade to the nucleus. By inhibiting the phosphorylation by erlotinib, the signal is stopped. EGFR is overexpressed in cells of certain types of human cancers - for example in lung cancer. This leads to inappropriate activation of the antiapoptotic Ras signalling cascade, eventually leading to uncontrolled cell proliferation. Research on gefitinib (Iressa ${ }^{\circledR}$ )-sensitive non-small cell lung cancers has shown that a mutation in the EGFR tyrosine kinase domain is responsible for activating anti-apoptotic pathways (27). These mutations tend to confer increased sensitivity to tyrosine kinase inhibitors such as gefitinib and erlotinib.

The concept of oral maintenance therapy, routinely used for $2-3$ years after remission in the treatment of childhood leukemia but up to now not in solid tumors, has recently been introduced in non-small cell lung cancer. In a prospective, randomized, double-blind placebo controlled study of almost 900 patients with non-small cell lung cancer, erlotinib significantly prolonged both progression-free and total survival in patients receiving stable disease after chemotherapy (28). The effect was seen in patients both with mutations in the EGFR and in wild type patients. Surprisingly, the effect was not seen in patients obtaining remission after the induction chemotherapy.

Sunitinib (Sutent $\left.{ }^{\circledR}\right)$ and sorafenib (Nexavar $\left.{ }^{\circledR}\right)$ target several different tyrosine kinases and were first approved for the treatment of advanced renal cancer, which is a tumor type with very low sensitivity to cytotoxic chemotherapy. Both drugs showed superior effects as compared to interferon alfa $(29,30)$. Sunitunib also targets KIT (CD117) and has activity in imatinib-resistant gastrointestinal stroma cell tumors (31). Sorafenib, inhibiting VEGF- and PDGF receptors as well as Raf also showed effect in a double-blind placebo controlled study in hepatocellular carcinoma (32).

Table 1 shows a number of tyrosine kinase inhibitors and the indication which was first approved.
Drug
First approved indication
axitinib
in clinical development (Pfizer)
crizotinib
in clinical development (Pfizer) 


$\begin{array}{ll}\text { dasatinib } & \text { Philadelphia chromosome positive chronic myelocytic leukaemi } \\ \text { erlotinib } & \text { lung cancer } \\ \text { gefitinib } & \text { lung cancer } \\ \text { imatinib } & \text { Philadelphia chromosome positive chronic myelocytic leukemia } \\ \text { lapatinib } & \text { breast cancer } \\ \text { neratinib } & \text { in clinical development (Pfizer) } \\ \text { nilotinib } & \text { Philadelphia chromosome positive chronic myelocytic leukemia } \\ \text { pazopanib } & \text { renal cancer } \\ \text { sorafenib } & \text { renal cancer } \\ \text { sunitinib } & \text { renal cancer } \\ \text { toceranib } & \text { mastocytoma in dogs }\end{array}$

In contrast to most cytotoxic chemotherapy, tyrosine kinase inhibitors are administered daily orally making them potentially suitable for therapeutic drug monitoring. But so far there have been few studies on the correlation between plasma drug concentrations and clinical effects and on the significance of polymorphisms in drug metabolising enzymes for the interindividual differences in drug effects. Erlotinib has a variable pharmacokinetics and is metabolized by CYP 3A4, CYP1A2 and CYP2C8 (33). Smoking markedly reduces plasma concentrations of erlotinib but this knowledge has not yet been incorporated in drug dosing in clinical routine.

\section{Monoclonal antibodies}

Monoclonal antibodies became a therapeutic possibility with the development of the hybridoma technique by Köhler and Milstein (34), However, severe obstacles for the therapeutic use were the rapid clearance of the murine derived antibodies by the reticuloendothelial system and the ability to cause allergic reactions in humans. The technique has now been improved so that chimeric or humanized monoclonal antibodies can be produced largely avoiding allergic reactions. By blocking growth factor receptors on the cell surface, antibodies can promote apoptosis or arrest tumor cell growth merely by binding their target. If other mechanisms like antibody dependent cell-mediated cytotoxicity and complement-dependent cytotoxicity contribute to the antitumoral effects is not clear. Rituximab (Mabthera®) was the first monoclonal antibody in cancer therapy (35). It is a chimeric monoclonal antibody which binds to the cluster of differentiation 20 antigen (CD20) 
and was approved by the FDA in 1997 for treatment of CD20-expressing lymphomas. The function of this antigen is not known but it is widely expressed on B cells, from early pre-B cells to later in differentiation, and it is absent on terminally differentiated plasma cells. It can therefore destroy B cells and is used in the treatment of many lymphomas.

Most monoclonal antibodies in cancer therapy bind and block a growth factor (like VEGF by bevacizumab, Avastin $®$ ) or a growth factor receptor (like HER2 by trastuzumab, Herceptin ${ }^{\circledR}$ or EGFR by cetuximab, Erbitux ${ }^{\circledR}$ and panitumumab, Vectibix $\left.{ }^{\circledR}\right)$. Trastuzumab is a success story in the treatment of breast cancers over expressing the HER2 receptor (about $15-20 \%$ of all breast tumors). Since HER2 is a growth factor, overexpression of its receptor is a bad prognostic marker. However, blocking the receptor by trastuzumab has been used for several years with great success in the palliative setting often in combination with a taxane (36). In recent years, trastuzumab has been introduced in the adjuvant setting with about $50 \%$ reduction in early relapses (37). However, it is too early to make the final conclusion about its value since it also has cardiotoxic effects and the long term consequences of this in not yet fully known.

Angiogenesis has long been an attractive target for drug development pioneered by Judah Folkman (38). Preclinical studies in tumor-bearing mice have given promising results but clinical trials were long disappointing. There are several potential reasons why success in preclinical studies has not been translated to success in the clinic. In mice, tumors are most often grown in an abnormal site. Tumor xenographs also contain newly formed blood vessels but in human tumors, the vasculature may have grown for years with different properties. After all, bevazicumab (Avastin $\left.{ }^{\circledR}\right)$ is the first marked drug with antiangiogenic effects binding to VEGF (39). It was first approved in colorectal cancer but is now also approved for breast, lung and renal cancer as well as for glioma (in US but not in Europe due to lack of results from comparative studies). Troublesome side effects are bleeding, hypertension and renal impairement.The pivotal study in breast cancer evaluated in an open study the addition of bevacizumab (10 mg/kg) on cycle days 1 and 15 to weekly paclitaxel $(90 \mathrm{mg} / \mathrm{m} 2)$ with one week intermission after each 3 -weeks cycle in more than 700 patients with metastatic breast cancer (40). An increase in progression-free survival from 5.9 to 11.8 months was seen but no effect on overall survival. On December 16, 2010, the FDA announced that the approval for Avastin ${ }^{\circledR}$ in breast cancer will be removed based on results of additional studies as required after the initial approval by the accelerated process. The judgement is that the limited 
effect on progression-free survival does not outweigh the risks of side effects like bleedings, hypertension and kidney failure. According to the European Medicines Agency, Avastin ${ }^{\circledR}$ remains a treatment option in breast cancer but only in combination with paclitaxel.

Cetuximab (Erbitux $\left.{ }^{\circledR}\right)$ is a chimeric monoclonal antibody against the EGF receptor and active in the treatment of colorectal and head and neck cancer. In metastatic colorectal cancer, cetuximab in combination with fluorouracil, leucovorin and oxaliplatin (FOLFIRI) improved response rates and disease free survival in patients with wild type K-ras, which encodes a small G-protein in the EGF receptor pathway (41). $60 \%$ of patients express the K-ras wildtype tumor. (42). Panitumumab (Vectibix) is a fully humanized antibody against the EGF receptor also depending on wild type K-ras for its effect in colorectal cancer (43)

Another monoclonal antibody under development is ipilimumab against metastasized malignant melanoma, a cancer type with very poor prognosis and little treatment progress throughout the years. Despite several years of clinical trials it is not until recently that the optimal dose was identified (44). A Phase III clinical trial found that patients with advanced, previously treated melanoma who received ipilimumab lived 34 percent longer than those in the comparative arm, who received a peptide vaccine. The trial is the first randomized study to show an improvement in survival in advanced melanoma, where few treatment options exist. Steven O'Day reported that ipilimumab alone or in combination with vaccine increased overall survival (OS) in patients with unresectable stage III/IV melanoma for whom previous treatment had failed (45)

Another concept under development in metastatic malignant melanoma is to inhibit the serine/threonine kinase B-raf. It is mutated in about $50 \%$ of melanomas and PLX4032 is a substance which inhibits mutated B-raf, The drug showed very good initial effects in a phase 2 study in 32 patients of which 25 had a partial and 2 a complete response (46). However resistance developed rapidly indicating that it is not enough to inhibit B-raf (47).

Table 2. Unconjugated monoclonal antibodies in cancer therapy

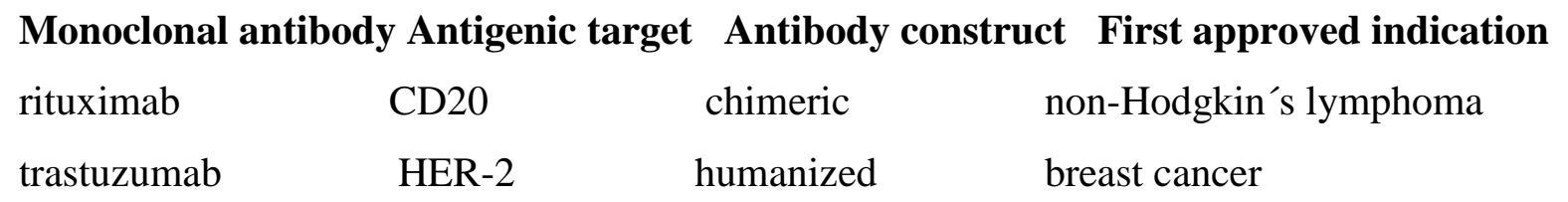




$\begin{array}{llll}\text { alemtuzumab } & \text { CD52 } & \text { humanized } & \text { chronic lymphocytic leukemia } \\ \text { bevacizumab } & \text { VEGF } & \text { humanized } & \text { colorectal cancer } \\ \text { cetuximab } & \text { EGFR } & \text { chimeric } & \text { colorectal cancer } \\ \text { panitumumab } & \text { EGFR } & \text { human } & \text { colorectal cancer } \\ \text { ipilimumab } & \text { CTLA-4 } & \text { human } & \text { in clinical trials against } \\ & & & \text { malignant melanoma }\end{array}$

\section{Targets in exploration}

The mammalian target of rapamycin (mTOR) plays a central role within a complex signalling network that controls cell growth and progression in all mammalian cells (48). It is a serine/threonine kinase, and activates protein translation pathways that lead to coordinated cell growth, division, metabolism and angiogenesis. Aberrant expression of the mTOR pathway is frequently detected in many cancers. Inhibition of mTOR offers a mechanism of action for intervening in pathways that are critical to tumor progression. The first mTOR inhibitor approved for clinical use in cancer is everolimus (Afinitor®) in renal cancer (49). It is also used to prevent graft rejection after organ transplantation.

The Notch signaling pathway represents a critical component in the control of cell growth during development (50). Aberrant activation of this pathway contributes to tumorigenesis. The role of Notch has been highlighted by the presence of activating mutations and amplification of Notch genes in human cancer and by the demonstration that genes in the Notch signaling pathway could be potential therapeutic targets. It has become clear that one of the major therapeutic targets in the Notch pathway is the Notch receptors, in which $\gamma$ secretase inhibitors prevent the generation of the oncogenic domain of Notch molecules and suppress the Notch activity.

Signaling through the insulin growth factor receptor 1 (IGFR-1) in normal cells leads to the activation of multiple intracellular pathways, mediated by the receptor-associated tyrosine kinase domain, by PI-3 kinase, and by serine/threonine kinase (Akt), yielding growth and enhanced survival (51). In cancer cells, IGFR-1 plays an even more critical role because it contributes to the promotion of tumor growth by inhibition of the apoptosis, transformation, metastasis, and induction of angiogenesis through the vascular endothelial growth factor (VEGF). 
Telomeres are specialized nucleoproteins at the end of chromosomes becoming shorter with each cell division leading to cellular senescence (52). The telomere length is maintained by telomerase, which is active in most human cancers and in germline cells but, with few exceptions, not in normal human somatic tissues. Interference with the telomerase maintenance of telomeres therefore represents an attractive and near universal target for cancer therapy. Treatment of cancer cells with inhibitors leads to progressive telomere shortening, with no acute cytotoxicity, but a proliferation arrest after a characteristic lag period with hallmarks of senescence, including morphological, mitotic and chromosomal aberrations and altered patterns of gene expression. Telomerase inhibition and telomere shortening also result in a marked reduction of the tumorigenic potential of drug-treated tumor cells in a mouse xenograft model (53).

Because cancer cells must proliferate, essential cell cycle proteins are attractive targets for cancer drugs. Cycline dependant kinases have been extensively screened for small molecule inhibitors and clinical trials are ongoing (54).

Approximately $50 \%$ of sporadic human tumors harbor somatic mutations in the p53 gene locus, while germ line mutations confer a high familial risk and are associated with the LiFraumeni syndrome. One of the most important functions of p53 is its ability to induce apoptosis, while disruption of this route can promote tumor progression and chemoresistance. The increasing understanding of the mechanisms of regulation of p53 may provide the basis for new drug designs that could eventually lead to therapeutics to reactivate p53 in cancer cells (55). A small molecule, PRIMA-1, reactivating mutated P53 has been described (56) and is now in phase 1 clinical trial.

\section{Short- and longterm toxicity}

The similarity in basic life processes between normal human cells and cancer cells implies that adverse drug reactions are inevitably connected to cytotoxic chemotherapy. Most adverse effects come from toxicity on growing cells in the bone marrow, gastrointestinal mucosa and hair follicles. Nausea and vomiting, earlier the most feared adverse effects by the patients, can now in most cases be well controlled by 5- $\mathrm{HT}_{3}$-receptor antagonists and corticosteroids (57). Recently NK1 receptor antagonists have been introduced with improved effect on delayed nausea and vomiting (58). The improved control of nausea and vomiting has also led to that 
most cancer chemotherapy can now be given in outpatient clinics reducing the need for hospital beds. Some drugs have characteristic side effects from other non-growing tissues like renal toxicity from cisplatin, cardiotoxicity from anthracyclines, neurotoxicity from taxanes and vinca alkaloids. The mechanisms behind these effects are not fully understood. Cisplatin treatment requires excessive hydration to prevent renal toxicity. The risk of antracycline cardiotoxicity is clearly dependant on the cumulative dose. Neurotoxicity is most often reversible. Patients cured for childhood ALL, Hodgkin's lymphoma, testicular cancer, and young women receiving adjuvant breast cancer generally have a long survival. With increased number of cancer survivors, the risk of developing late effect of a curative treatment becomes more important and requires efficient follow-up systems. Will full-dose anthracycline chemotherapy 40 years ago increase the risk of cardiac failure is an example of questions which need to be addressed.

The targeted drugs are not devoid of side effects but have a different side effect profile as compared to the conventional cytotoxic drugs. Most common is skin rashes. The targets for these drugs are often expressed in normal cells and there are data indicating that the degree of skin rashes correlates to the antitumour effect.

\section{Clinical trials in cancer}

The development of combinations of conventional chemotherapeutics can be described as a laborious trial and error work. Some principles for the treatment design can be identified: The drugs should be active as single agents, they should have different mechanisms of action and different dose-limiting toxicities, which is not easy to fulfil since most cytotoxic drugs have bone marrow toxicity as dose limiting effect. The number of possible combinations is enormous, including the selection of 2 to 4 drugs to be combined, choice of doses and schedules and it is impossible to test them all in large clinical trials. Another problem with clinical trials in cancer chemotherapy is that the initial trials of a new drug for ethical reasons have to be performed on severely ill patients already treated with the most effective standard regimens. Since resistance to one drug is often accompanied by cross-resistance to other drugs, it is possible that drugs highly effective in chemotherapy-naïve patients could very well be overlooked.

For trials of targeted drugs, it is of course important to select the patients expressing the targets which means that collection and testing of tumor tissue samples must be done before 
the patient can be included. A possible shortcut is the introduction of phase 0 trials which are first in man exploratory trials with microdoses to small groups of patients with the aim to test if the drug is behaving in cancer patients as predicted from experimental studies eg inhibiting the proposed target enzyme (59). However, phase 0 trials do not give information about efficacy or toxicity.

The endpoints in clinical trials in cancer patients may also cause interpretation problems. Overall survival is the most robust endpoint but it is influenced by the effect of the next treatment line after progression on the new treatment. Furthermore, in many trials, patients progressing on the control treatment are allowed to swich to the new treatment after progression reducing the difference between the treatments. One common endpoint is "progression free survival" but this is of course influenced by the frequency of treatment evaluation which can make comparisons between trials difficult. Quality of life evaluation is now regularly included in the trial design of anticancer therapies.

In some cancer forms like renal cancer, several tyrosine kinase inhibitors have been introduced. Similarly cetuximab and panitumumab are monoclonal antibodies against the EGF receptor both depending on wild type K-ras. From a society perspective one would like to see head-to-head comparisons between similar drugs but the pharmaceutical complanies are not interested in such studies so this has to be performed by academic groups which is difficult due to high costs.

\section{Personalized chemotherapy}

In cancer chemotherapy, it is important to select the best treatment from the very beginning since tumor progression and development of resistance makes it harder to achieve a good result. The human tumor stem cell assay developed by Salmon and Hamburger (60) attracted much interest for the potential to individualize the treatment based on in vitro drug sensitivity testing as has been routine for decades in antibacterial chemotherapy. It was found that collagenase treatment can produce single cell suspension of solid tumors and allowed the cells to divide a few times and form colonies when grown in soft agar. Treatment of the cells with a number of drugs at various concentrations before plating in agar allowed the determination of the sensitivity pattern of the individual patient's tumor by comparing the inhibition of colony formation. Since the drug sensitivity of cells with proliferative potential was tested, the concept was initially met by great enthusiasm. However, difficulties were soon evident; 
laborious technique with slow growth of colonies so that tests could only be evaluated after 3 weeks, difficulties to obtain colonies from untreated cells for many tumor types. The introduction of non-clonogenic short term assays overcame some of the disadvantages with the clonogenic assays. Examples are the colorometric tetrazolium based assays such as MTT, the fluorometric microculture cytotoxicity assay FMCA, the morphological differential staining cytotoxicity assay (DiSC) all of which are based on differences in staining ability between living and dead cells. They are rapid and need only $2-4$ days of culture and can to some extent be automated. The principal disadvantage is that they are performed on total cell populations consisting mainly of non-dividing cells. In vitro drug sensitivity testing has not been successful enough to reach clinical routine due to the heterogeneity of the human tumors. The curative potential of a specific treatment is dependant on the effect on the least sensitive cell clone and this is difficult to evaluate in the available tests.

Tumors are so far characterized by clinical stage (size, metastatic pattern) and morphologic appearance in the microscope. The large variability in treatment response strongly indicates that other factors are important predictors for response to therapy. Development in molecular biology techniques makes it possible to characterize tumors by gene expression patterns, microarrays. Predictive gene expression signatures have been described in certain tumors. In young breast cancer patients, a 70-gene tumor expression profile has been described (61). However this procedure has not yet reached clinical routine and there is little concordance between predictive signatures in different studies of the same tumor type. One difficulty is the large normal interpatient variability and the expression pattern is the combined result of tumor and normal cells.

Cytotoxic drugs are administered at doses close to their maximal tolerable dose and therapeutic windows are narrow, minor differences in individual drug handling may lead to severe toxicities. Therefore pharmacogenetic studies can be expected to form a basis for individualized treatment (Table 3). The best example is phenotyping and/or genotyping of thiopurine methyltransferase (TPMT) before initiating thiopurine therapy (62).

Table 3. Examples of therapeutically relevant genetic variations in oncology

\section{Genetic variant}

Estrogen and progesterone receptors

K-ras

\section{$\operatorname{Drug}(\mathbf{s})$}

antiestrogens

cetuximab, panitumumab

\section{Consequence for}

tumor response

tumor response 


$\begin{array}{lll}\text { HER-2 amplification } & \text { trastuzumab } & \text { tumor response } \\ \text { 9:22 translocation } & \text { imatinib } & \text { tumor response } \\ \text { c-kit variant } & \text { imatinib } & \text { tumor response } \\ \text { Thiopurine methyltransferase } & \text { thiopurines } & \text { leukopenia } \\ \text { Dihydropyrimidine dehydrogenase } & \text { 5-flurouracil, capecitabin } & \text { leukopenia } \\ \text { CYP2D6 } & \text { tamoxifen } & \text { reduced active metabolite } \\ \text { UGT1A1 } & \text { irinotecan } & \text { leukopenia }\end{array}$

For the new targeted drugs, it is important to identify the patients expressing the relevant target in high concentration or at least surrogate biomarkers. This requires investigation of tumour biopsies. It has been clinical routine since long to quantitate the HER2 expression in breast cancer. It is known that monoclonal antibodies against the EGF-receptor in colorectal cancer (cetuximab and panitumumab) do not act on tumours with mutations in the oncogene K-ras. Therefore these drugs are only approved for treatment of patients with wild type K-ras. On the other hand, erlotinib and gefitinib are more effective in lung cancer patients with mutations in the EGF receptor.

\section{High-dose chemotherapy}

The dose-response relationships in experimental systems led to attempts to increase cytotoxic dose and rescue the bone marrow by stem cell transplantation either autologous transplantation by the patient's own cells harvested before high dose chemotherapy or allogenic transplantation from a closely related donor. Thereby the dose-limiting bone marrow toxicity can be overcome. The clinical results have, however, been disappointing. The most likely reason is that patients have first received conventional chemotherapy with the risk of developing resistance. If the high dose chemotherapy could be done up-front, the potential would be much better.

\section{Hormonal therapies}

The growth of tumor cells from breast cancer, endometrial carcinoma and prostate cancer is often stimulated by hormone signalling. Several drugs have been developed with a mechanism of action antagonizing the growth stimulatory effect of hormones. This is the case for antiestrogens and aromatase inhibitors in the treatment of breast cancer, and LHRHantagonists in the treatment of prostate and breast cancer. Glucocorticoids have cytotoxic 
effects on lymphatic malignancies. Tamoxifen itself is a prodrug, having very little affinity for its target protein, the estrogen receptor (63) It must first be metabolized in the liver by the cytochrome P450 isoform CYP2D6 into the active metabolites 4-hydroxytamoxifen and des$\mathrm{N}$-methyl-4-hydroxytamoxifen (endoxifen). These active metabolites compete with estrogen in the body for binding to the estrogen receptor so that transcription of estrogen-responsive genes is inhibited. In postmenopausal women, estrogens are formed from androgen precursors from the adrenal cortex by the action of aromatase. This production of estrogens can be inhibited by aromatase inhibitors. Tamoxifen and aromatase inhibitors are also used in the adjuvant setting. Tamoxifen treatment implies an increased risk for thromboembolic events. Osteoporosis is a well documented side effect of aromatase inhibtors which is of concerns for the long term adjuvant treatment. A recent study has shown improved 5-years-result with anastrozol, an aromatase inhibitor compared to tamoxifen in the adjuvant setting (64).

\section{Cancer stem cells}

Cancer stem cells are small populations of cells within tumors believed to be responsible for initiating tumor growth, recurrence and metastasis. Cancer stem cells are capable of indefinite self-renewal, because of high telomerase activity, and can differentiate into all cells found in a particular tumor type. Cancer stem cells show resistance to standard chemotherapeutic agents that are effective against bulk tumor cells. After initial reduction of a tumor by standard treatments, the tumor may re-grow as a result of cancer stem cell proliferation and differentiation, causing relapse of the disease. Cancer stem cells are therefore important targets for novel therapies.

\section{Complementary and alternative therapies}

Since cancer often is a fatal disease, it is not surprising that patients can be attracted by various unconventional therapies advocated for by charismatic individuals or groups. Complementary and alternative medicine includes a broad range of healing philosophies, approaches, and therapies. One study in 453 cancer patients showed that $69 \%$ had used at least one complementary or alternative treatment (65). Well-known drugs used are mistletoe extracts used in anthroposophical medicine and Laetrile, extract from apricot kernels. It is important that the same rigorous scientific evaluation used to assess conventional approaches be used to evaluate complementary and alternative therapies. The National Cancer Institute is funding a number of clinical trials at medical centers in the US to evaluate such therapies for cancer. 
Future perspectives The discovery that certain toxic chemicals administered in combination can cure certain cancers ranks as one of the greatest in modern medicine. However, the hopes created by the initial success of cancer chemotherapy were not fully borne out, as conventional cytotoxic chemotherapy has fallen short of the high expectations of curing the most common cancers. The drugs are unspecific and toxic effects on normal cells lead to dose-limiting adverse effects especially on the bone marrow. Development of resistance is another major obstacle to successful treatment. Novel knowledge about the molecular biology of cancer and new tools to specifically target aberrant proteins are opening up new treatment options. Today hundreds of monoclonal antibodies and small molecules directed against receptors and signal transduction pathways are in different phases of development. This development will accelerate as the basic understanding of signal transduction will increase. The basic biological problem is, however, the instability of the cancer cell genome. Therefore, it is unlikely that a single drug alone will lead to cure of most patients with a certain diagnosis. Imatinib in CML should probably be regarded as an exception. Future drug therapy should take into account the mutation pattern in the tumor for selection of drugs and the constitution of the patient for dosing of the selected drugs. Not only tumor tissue but also normal tissue should be biobanked for determination of the SNPs influencing the function of metabolic enzymes and drug transporters.

Early treatment start is important to limit tumor progression and heterogeneity. Development of screening techniques with high specificity is therefore important and new visualization techniques like PET-CT are valuable for the detection of spread disease making curative surgery impossible. The concept of adjuvant therapy, first introduced in breast cancer, is now under development for other diseases, eg colorectal and lung cancer and the challenge for the future will be to develop improved prognostic means to limit the treatment to those who are at high risk of relapse. Establishing of comprehensive cancer centers with radiologists, pathologists, surgeons, medical oncologists and radiotherapists is cruzial to develop optimal multidisciplinary handling of patients.

\section{References}

1. Ferlay J, Autier P, Boniol M et al (2007) Estimates of the cancer incidence and mortality in Europe in 2006. Annals of Oncology 18:581-592 
2. Berrino F, De Angelis R, Sant M et al (2007) Survival for eight major cancers and all cancers combined for European adults diagnosed in 1955-99: results of the EUROCARE-4 study. The Lancet Oncology 8: 773-783

3. Shoemaker R H (2006) The NCI60 human tumour cell line anticancer drug screen. Nature Reviews Cancer 6: 813-823

4. Mellor HR, Callaghan R (2008) Resistance to chemotherapy in cancer: A complex and integrated cellular response. Pharmacology 81: 275-300

5. Kaye SB (2008) Reversal of drug resistance in ovarian cancer: Where do we go from here? J Clin Oncol 26: 2616-2618

6. Rosenberg B, Van Camp L, Grimley EB et al (1967) The inhibition of growth or cell division in Escherichia coli by different ionic species of platinum(IV) complexes.

J Biol Chem 242: 1347-1352

7. Rosenberg B, VanCamp L, Trosko JE et al (1969) Platinum compounds: a new class of potent antitumour agents. Nature 222: 385-386

8. Minotti G, Menna P, Salvatorelli E et al (2004) Anthracyclines: molecular advances and pharmacologic developments in antitumor activity and cardiotoxicity. Pharmacol. Rev. 56: $185-229$.

9. Heidelberger C, Ansfield FJ (1963) Experimental and clinical use of fluorinated pyrimidines in cancer chemotherapy. Cancer Res 23:1226-1243

10. Elion GB (1989) The purine path to chemotherapy. Science 244: 41-47

11. Plunkett W, Heinemann V, Estey E, Keating M (1990) Pharmacologically directed design of leukemia therapy. Haematol Blood Transfus 33: 610-613

12. Carmichael J (1998) The role of gemcitabine in the treatment of other tumors. Br J Cancer 78 suppl 3: 21-25

13. McLeod, HL, Cassidy J, Powrie R H et al (2000) Pharmacokinetic and pharmacodynamic evaluation of the glycinamide ribonucleotide formyltransferase inhibitor AG2034. Clinical Cancer Research 6: 2677-2684

14. Vogelzang NJ, Rusthoven JJ, Symanowski J, et al (2003) Phase III study of pemetrexed in combination with cisplatin versus cisplatin alone in patients with malignant pleural mesothelioma. J Clin Oncol. 21:2636-2644.

15. Scagliotti GV, Parikh P, von Pawel J et al (2008) Phase III study comparing cisplatin plus gemcitabine with cisplatin plus pemetrexed in chemotherapy-naive patients with advancedstage non-small-cell lung cancer. J Clin Oncol 26:3543-3551. 
16. Petrelli F, Borgonovo K, Barni S (2010) Targeted delivery for breast cancer therapy: the history of nanoparticle-albumin-bound paclitaxel. Expert Opin Pharmacother 11:1413-1432. 17. De Bono JS, Oudard S, Ozguroglu M (2010) Cabazitaxel or mitoxantrone with prednisone in patients with metastatic castration-resistant prostate cancer (mCRPC) previously treated with docetaxel: Final results of a multinational phase III trial (TROPIC). J Clin Oncol 28:15s abstract 4508 .

18. Gautschi O, Heighway J, Mack PC et al (2008) Aurora kinases as anticancer drug targets. Clin Cancer Res 14: 1639-1648

19. Skipper H, Schabel F, Wilcox W (1964) Experimental evaluation of potential anticancer agents. Cancer Chemother Rep 35: 1-111

20. De Vita VT, Serpick A, Carbone PP (1970) Combination chemotherapy in the treatment of advanced Hodgkin's disease. Ann Intern Med 73: 881-895

21. Einhorn L (2002) Curing metastatic testicular cancer. PNAS 99: 4592-4595

22. Bonadonna G, Brusamolino E, Valagussa P et al (1976) Combined chemotherapy as adjuvant treatment in operable breast cancer. New Engl J Med 294: 405-410

23. Bonadonna G, Moliterni A, Zambetti M et al (2005) 30 Years' follow up of randomised studies of adjuvant CMF in operable breast cancer: cohort study. BMJ 330: 217

24. Druker BJ, Lydon NB (2000) Lessons learned from the development of an Abl tyrosine kinase inhibitor for chronic myelogenous leukemia. J Clin Invest 105:3-7

25. Druker B, Guilhot F, O’Brian S et al (2006). Five-year follow-up of patients receiving imatinib for chronic myeloid leukemia. N Engl J Med; 355: 2408-2417

26. Pollack VA, Savage DM, Baker DA et al (1999) Inhibition of epidermal growth factor receptor-associated tyrosine phosphorylation in human carcinomas with CP-358,774:

dynamics of receptor inhibition in situ and antitumor effects in athymic mice. J Pharmacol Exp Ther 291: 739-748

27. Baselga J, Averbuch SD (2000) ZD1839 ('Iressa') as an anticancer agent. Drugs 60 suppl 1: $33-40$

28. Cappuzzo F, Ciuleanu T, Stelmakh L et al (2010) Erlotinib as maintenance treatment in advanced non-small-cell lung cancer: a multicentre, randomised, placebo-controlled phase 3 study. Lancet Oncol 11:521-529. 29. Motzer RJ, Hutson TE, Tomczak P, Michaelson MD, Bukowski RM, Rixe O, Oudard S, et al (2007) Sunitinib versus interferon alfa in metastatic renal-cell carcinoma. N Engl J Med. 356:115-124. 
30. Escudier B, Eisen T, Stadler WMet al (2007) Sorafenib in advanced clear-cell renal-cell carcinoma. N Engl J Med. 356:125-134.

31. Demetri GD, van Oosterom AT, Garrett CR et al (2006) Efficacy and safety of sunitinib in patients with advanced gastrointestinal stromal tumour after failure of imatinib: a randomised controlled trial. Lancet 368:1329-1338.

32. Llovet JM, Ricci S, Mazzaferro V et al (2008) Sorafenib in advanced hepatocellular carcinoma. N Engl J Med_359:378-90.

33. Hamilton M, Wolf JL, Rusk J et al (2006) Effects of smoking on the pharmacokinetics of erlotinib. Clin Cancer Res.12: 2166-2171.

34. Köhler G and Milstein C (1975) Continuous cultures of fused cells secreting antibody of predefined specificity Nature 256: 495-7

35. Grillo-López AJ, White CA, Varns C et al (1999) Overview of the clinical development of rituximab: first monoclonal antibody approved for the treatment of lymphoma. Semin Oncol. 5 Suppl 14: 66-73.

36. Goldenberg MM (1999) Trastuzumab, a recombinant DNA-derived humanized monoclonal antibody, a novel agent for the treatment of metastatic breast cancer. Clin Ther 2: $309-318$

37. Garnock-Jones KP, Keating GM, Scott LJ (2010) Trastuzumab: A review of its use as adjuvant treatment in human epidermal growth factor receptor 2 (HER2)-positive early breast cancer. Drugs 70: 215-239

38. Folkman J (1972) Anti-angiogenesis: new concept for therapy of solid tumors. Ann Surg 175: $409-416$

39. Ferrara N, Hillan KJ, Gerber HP, Novotny W (2004) Discovery and development of bevacizumab, an anti-VEGF antibody for treating cancer. Nat Rev Drug Discov 3: 391-400 40. Miller K, Wang M, Gralow J et al (2007) Paclitaxel plus bevacizumab versus paclitaxel alone for metastatic breast cancer. N Engl J Med 357: 2666-2676

41. Van Cutsem E, Köhne CH, Hitre E et al (2009) Cetuximab and chemotherapy as initial treatment for metastatic colorectal cancer. N. Engl. J. Med. 360: 1408-1742. Soulières D, Greer W, Magliocco AM et al (2010) KRAS mutation testing in the treatment of metastatic colorectal cancer with anti-EGFR therapies. Curr Oncol. 17 Suppl 1: S31-40.

43. Rowinsky EK, Schwartz GH, Gollob JA (2004) Safety, pharmacokinetics, and activity of ABX-EGF, a fully human anti-epidermal growth factor receptor monoclonal antibody in patients with metastatic renal cell cancer. J Clin Oncol 22: 3003-15 
44. Wolchok JD, Neyns B, Linette G (2010) Ipilimumab monotherapy in patients with pretreated advanced melanoma: a randomised, double-blind, multicentre, phase 2, doseranging study. Lancet Oncol. 11: 155-64.

45 O'Day F S, Hodi, D F, McDermott R W et al (2010) A phase III, randomized, doubleblind, multicenter study comparing monotherapy with ipilimumab or gp100 peptide vaccine and the combination in patients with previously treated, unresectable stage III or IV melanoma. J Clin Oncol 28:18s, 46. Flaherty KT, Puzanov I, Kim KB et al (2010) Inhibition of mutated, activated BRAF in metastatic melanoma. N Engl J Med 363:809-819.47.

47. Nazarian R, Shi H, Wang Q, Kong X, Koya RC, Lee H, Chen Z et al (2010) Melanomas acquire resistance to B-RAF(V600E) inhibition by RTK or N-RAS upregulation. Nature. 468:973-977.

48. Sparks CA, Guertin DA. (2010) Targeting mTOR: prospects for mTOR complex 2 inhibitors in cancer therapy. Oncogene 29:3733-3744.

49. Houghton PJ (2010) Everolimus. Clin Cancer Res 16:1368-1372

50. Yin L, Velazquez OC, Liu ZJ (2010) Notch signaling: emerging molecular targets for cancer therapy. Biochem Pharmacol 80: 690-701

51. Gualberto A, Pollak M (2009) Emerging role of insulin-like growth factor receptor inhibitors in oncology: early clinical trial results and future directions. Oncogene 28: 3009-21 52. Murnane JP (2010) Telomere loss as a mechanism for chromosome instability in human cancer. Cancer Res. 70: 4255-9.

53. Shay JW, Keith WN (2008) Targeting telomerase for cancer therapeutics. Br J Cancer 98: 677-83

54. Malumbres M, Barbacid M (2009) Cell cycle, CDKs and cancer: a changing paradigm. Nat Rev Cancer 9: 153-66.

55. Nahi H, Selivanova G, Lehmann S et al (2008) Mutated and non-mutated TP53 as targets in the treatment of leukaemia. Br J Haematol 141: 445-453.

56. Lambert JM, Gorzov P, Veprintsev DB et al (2009) PRIMA-1 reactivates mutant p53 by covalent binding to the core domain. Cancer Cell 15: 376 - 388

57. Herrstedt J (2008) Antiemetics: an update and the MASCC guidelines applied in clinical practice. Nature Clinical Practice Oncology, 5: 32 - 43 
58. Hesketh PJ (2001) Potential role of the NK1 receptor antagonists in chemotherapyinduced nausea and vomiting. Support Care Cancer 9:350-354

59. Murgo AJ, Kummar S, Rubinstein L, et al (2008) Designing phase 0 cancer clinical trials. Clin Cancer Res 14: 3675 - 368260. Hamburger AW, Salmon SE (1977) Primary bioassay of human tumor stem cells. Science, 197: 461-463

61. Glas AM, Floore A, Delahaye JMJ et al (2006) Converting a breast cancer microarray signature into a high-throughput diagnostic test. BMC Genomics 7: 278

62. Dewit O, Starkel P, Roblin X (2010) Thiopurine metabolism monitoring: implications in inflammatory bowel diseases. Eur J Clin Invest. $2010 \mathrm{Jul}$ 13. [Epub ahead of print] 63. Desta Z, Ward BA, Soukhova NV, Flockahart DA (2004) Comprehensive evaluation of tamoxifen sequential biotransformation by the human cytochrome P450 system in vitro: prominent roles for CYP3A4 and CYP2D6. J

Pharmacol Exp Ther 310: 1062 - 1075.

64. Howell A, Cuzick J, Baum M, et al (2005) Results of the ATAC (Arimidex, Tamoxifen, Alone or in Combination) trial after completion of 5 years' adjuvant treatment for breast cancer. Lancet 365: 60-62.

65. Richardson MA, Sanders T, Palmer JL et al (2000) Complementary/alternative medicine use in a comprehensive cancer center and the implications for oncology. J Clin Oncol 18: $2505-2514$ 